\title{
Bunchgrass basal area affects selection of plants by cattle
}

\author{
DAVID GANSKOPP AND JEFF ROSE
}

\begin{abstract}
Authors are range scientists, USDA-ARS, Eastern Oregon Agricultural Research Center, Squaw Butte Station, HC 714.51 Hwy. 205, Burns, Ore. 97720; and research assistant, Oregon State University, Eastern Oregon Agricultural Research Center, Squaw Butte Station, HC 714.51 Hwy. 205, Burns 97720.
\end{abstract}

\begin{abstract}
Cattle are selective foragers in response to several plant attributes. We tested hypotheses that caespitose plants of various basal areas were equally susceptible to herbivory and were defoliated with equal intensity by cattle. Five-hundred crested wheatgrass (A gropryon desertorum (Fischer ex Link) Schultes) plants, distributed among 10 basal area classes, were monitored for frequency and level of utilization after approximately $74 \%$ of all plants in pastures were grazed by cattle. Plants with $<25-\mathrm{cm}^{2}$ basal area were less likely, and plants between 65 and $105-\mathrm{cm}^{2}$ more likely to be grazed than other classes. Ninety-one percent of the 65 to $85-\mathrm{cm}^{2}$ basal area plants were defoliated, while only $48 \%$ of those $<2.5 \mathrm{~cm}^{2}$ were grazed. The fact that mid-size plants occurred least often but were defoliated most often lends further credence to the selective grazing hypothesis. Less frequent use by cattle of plants $<25-\mathrm{cm}^{2}$ basal area may enhance chances of seedling establishment and survival of smaller established plants or remnants of deteriorating tufts. Among grazed plants, however, smaller plants endured higher utilization by weight than the overall population. Utilization was equal among other size classes. Because forage yield per unit of basal area declined as plant size increased, cattle probably forage most efficiently by selecting bite-size plants. Researchers using single plants, tiller, or leaves as experimental units should note that varying sized tufts are not equally likely to be defoliated, and plants less than $25-\mathrm{cm}^{2}$ basal area may receive greater than average levels of utilization from free-ranging cattle under light to moderate utilization levels. These aspects of livestock grazing behavior and research objectives should be considered in selection of experimental units.
\end{abstract}

Key Words: Agropyron desertorum (Fischer ex Link) Schultes, crested wheatgrass, palatability, forage preference, optimum foraging

Selective livestock grazing has diverse and far-reaching implications for stockmen, resource managers, and researchers. Knowledge that specific species, plants, or plant parts will be grazed provides insight into various facets of diet quality, stocking rates, livestock distribution, and effects of defoliation on the subsequent well-being of forage plants. Selective grazing has long been accepted as fact in mixed composition pastures (Marten 1969), but only recently has it been acknowledged in monotypic pastures. Norton and Johnson $(1981,1986)$ and others have observed the relationship between plant size and stature and probability of defoliation by cattle. Cattle were also less likely to tread on plants, particularly taller tussocks, than on barren interspaces or directly on heavily cropped plants (Balph and Malechek 1985, Balph et al. 1989). Because much research is presently focused on use of individual plants, tillers, or leaves, it is important that our designs, data, and interpretations not be confounded by unrecognized,

Technical Paper 9799. Oregon Agricultural Experiment Station.

Manuscript accepted 15 Apr. 1992. selective grazing by livestock.

Norton and Johnson (1981 and 1986) reported cattle preferred grazing medium-size ( 11 to $200-\mathrm{cm}^{2}$ basal area) crested wheatgrass (Agropyron desertorum (Fischer ex Link) Schults and A. cristatum (L.) Gaertner) while avoiding smaller and larger tufts. They noted that the presence of standing dead stems in the larger tufts may have contributed to livestock avoidance (Norton et al. 1982). Norton et al. (1983) later reported that removal of standing dead culms eliminate selective grazing of plants having basal areas between 20 and $314 \mathrm{~cm}^{2}$. Further research found no avoidance of larger plants when $90 \%$ of all plants were defoliated, but correlations relating defoliation percentages and presence of standing culms were inconsistently detected (Hacker et al. 1988). The objective of our research was to establish the degree of sensitivity of cattle to bunchgrass size, as indexed by basal area, without the confounding influences of standing dead reproductive stems or straw.

\section{Materials and Methods}

The study was conducted on the Squaw Butte Experimental Range $72-\mathrm{km}$-west-southwest of Burns, Ore. $\left(119^{\circ} 43^{\prime} \mathrm{W}, 43^{\circ} 29^{\circ} \mathrm{N}\right)$ on a crested wheatgrass (Agropyron desertorum (Fischer ex Link) Schultes) pasture established in 1970. Elevation is approximately $1,370 \mathrm{~m}$ with a mean annual precipitation of $283 \mathrm{~mm}$. Milican fine sandy loam soil (coarse-loamy, mixed, frigid Orthidic Durixerolls) (Lentz and Simonson 1986) characterizes the area. These data were taken from a larger research project focused on the selective response of cattle to pre-determined densities of cured reproductive stems in crested wheatgrass at 3 stages of phenology (Ganskopp et al. 1992). Data include plants from trials during late-boot and anthesis stages of phenology, from which all residual cured stems and straw were removed, and plants from quiescence, which contained some cured stems. Cattle were oblivious to cured stems, however, after plants entered quiescence. Data were acquired during the 1989 (9 pastures) and 1990 (8 pastures) grazing seasons. Crop-year (September-June) precipitation for the 1989 and 1990 growing seasons was, respectively, 106 and $66 \%$ of the long term mean $(257 \mathrm{~mm})$.

Pastures ranged between 0.6 and $0.7 \mathrm{ha}$, and 4 line transects, totaling $400 \mathrm{~m}$, were established in each pasture. Before pastures were grazed, the greatest basal diameter and a second diameter, perpendicular to the first, were measured on plants growing closest to randomly selected points along transects. Basal area was determined by solving for the area of an ellipse. During both the late-boot and anthesis periods, standing crop was harvested from 25 additional plants distributed among 5 basal area size classes, and regressions calculated to determine the relationship between basal area and forage biomass.

Two yearling steers (1989) or mature cows (1990) were placed in each pasture for 4 or 5 days and allowed to graze until approxi- 
mately $75 \%$ of all plants in the pasture received some degree of defoliation. Numbers of grazed and ungrazed plants were monitored daily via step-point sampling of 25 points in each pasture until 75\% defoliation occurred. We believed this level of grazing would place reasonable demands on the forage resource and yet allow cattle some opportunity to graze selectivity since ungrazed plants were still available. Cattle were then removed, line transects reestablished, and the designated plants evaluated for evidence of defoliation. If defoliated, the percent of utilization by weight was estimated using height-weight relationships (Heady 1950) developed each year at each phenological stage.

For analyses, data were sorted among 10 arbitrarily selected size classes. These included: 1 class with bounds from 0 to $5 \mathrm{~cm}^{2}$ basal area, 7 classes between 5 and $145 \mathrm{~cm}^{2}$ incremented in $20 \mathrm{~cm}^{2}$ units, 1 class from 145 to $200 \mathrm{~cm}^{2}$, and plants greater than $200 \mathrm{~cm}^{2}$ basal area. Chi-square analysis of independence $(P<0.05)$ was used to test the null hypothesis that frequencies of defoliated and nondefoliated plants were independent of basal area. When the null hypothesis was rejected, simultaneous confidence intervals (Miller 1966, Snedecor and Cochran 1967) for differences between proportions $(P<0.05)$ were derived, via the Bonferroni approach, to test the hypothesis that plants within each size class were defoliated with greater, equal, or lesser frequency than the population mean. A second chi-square analysis examined the hypothesis that the number of plants grazed was independent of the number of plants available within size classes. Degree of association between class rankings based on the number of plants grazed and the number of plants occurring within size classes was indexed with Spearman's rank correlation coefficient. We tested the hypothesis that levels of utilization within size classes approximated the population mean with 2 separate $t$-tests. The first included all plants within each class, while the second included only the grazed plants.

Because these hypotheses are related to the mouth size of cattle and no published dimensions of their biting surfaces could be found, we measured the outside width of the incisors of 10 animals in each of 3 age classes. These were: 2, 3, and 4+ year old Hereford $X$ Angus cattle. Their heads were immobilized with a squeeze chute and measurements taken with a ruler to the nearest millimeter.

\section{Results and Discussion}

Mean basal area of the 500 crested wheatgrass plants was 100.1 $\mathrm{cm}^{2}$, with a median value of 62.8 and a range of 0.59 to $874 \mathrm{~cm}^{2}$. Plants in the 15 and $>200-\mathrm{cm}^{2}$ classes occurred most frequently, while the $95-\mathrm{cm}^{2}$ class constituted the smallest contribution (5.4\%) to the population (Fig. 1). Forage density or plant production per

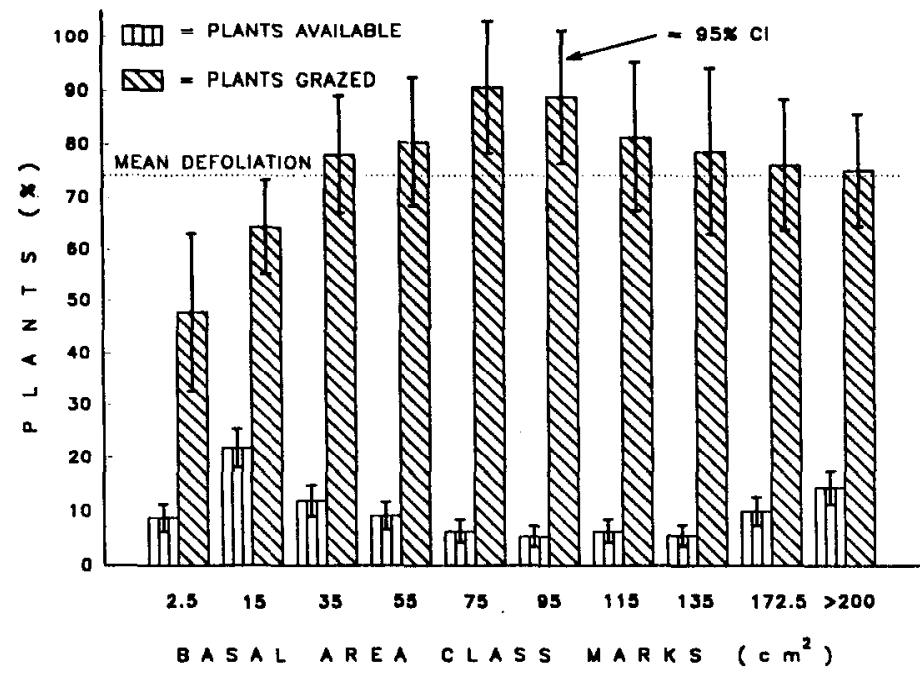

Fig. 1. Availability and percent of crested wheatgrass plants grazed by cattle in 10 basal area size growing near Burns, Ore. unit of basal area was negatively associated with increasing basal area at both late-boot and anthesis sampling periods (Fig. 2). Linear models predicted yield per unit of basal area of smaller plants $\left(\leq 75 \mathrm{~cm}^{2}\right)$ was 40 to $50 \%$ greater than that of large $(\leq 275$ $\mathrm{cm}^{2}$ ) tufts. Sample integrity was not maintained, however, and we

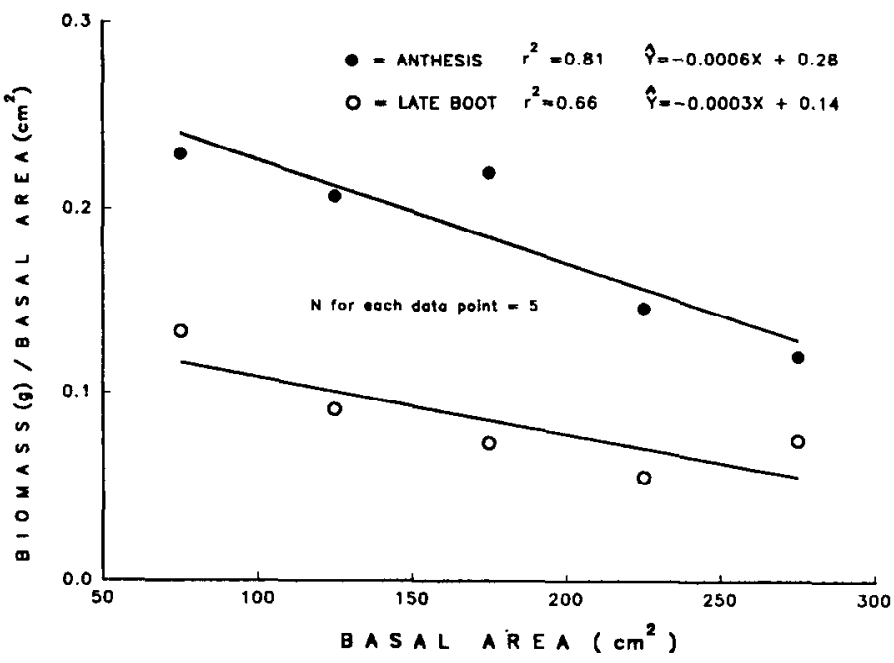

Fig. 2. Relationships between crested wheatgrass basal area and forage yield per unit of basal area at 2 stages of phenology near Burns, Ore.

could not determine whether these relationships were due to differences in tiller size, tiller density, or number of leaves within larger tufts.

When averaged across all size classes, $73.6 \%$ of the plants were grazed (Fig. 1). Plants in the $75-\mathrm{cm}^{2}$ basal area class were grazed most often $(91 \%)$, and the $2.5-\mathrm{cm}^{2}$ class defoliated least (48\%). Chi-square analysis rejected our null hypothesis, indicating that grazing by cattle was not independent of plant size $\left(X^{2}=31.5,9 \mathrm{df}\right.$, $P<0.01)$. Confidence intervals revealed the 2 smallest size classes were defoliated less often than the population mean (Fig. 1), while plants in the 75 and $95-\mathrm{cm}^{2}$ classes were defoliated at greater than expected frequencies $(P<0.05)$. Cattle did not discriminate among the remaining classes, which included plants in the $>200 \mathrm{~cm}^{2}$ category.

Based on chi-square analysis we accepted the null hypothesis that the number of plants grazed and the number of plants occurring within size classes were unrelated $\left(\mathrm{X}^{2}=7.2,9 \mathrm{df}, P>0.05\right)$. A significant $(P<0.05)$ Spearman's rank correlation coefficient $\left(r_{s}=\right.$ -0.66 ), however, implied that frequency of occurrence and probability of defoliation were indeed negatively correlated. Figure 1 illustrates that plants with the greatest likelihood of being defoliation occurred in classes having the fewest individuals, with the reciprocal also being true.

Mean forage utilization levels of pastures derived from our clipping data $(23 \% \pm 7.9,95 \% \mathrm{CI})$ closely approximated the means based on measures of individual grazed plants (Fig. 3). Utilization was similar among size classes when all plants, both grazed and ungrazed, were included in analyses $(P>0.05)$. When only grazed plants were considered, however, a significant $(P<0.05)$ departure from the mean occurred in the smallest size class, where utilization was greater than average. Across all classes, mean disparity between utilization estimates derived from all plants and grazed plants only was $5.4 \%( \pm 2.28,95 \% \mathrm{CI})$, with a significant difference between the 2 methods occurring, again, only in the smallest class.

Our interpretations conform with those of Norton and Johnson $(1981,1986)$ and Hacker et al. (1988) with some minor disparities due to differences in sward structure, dimensions of size classes, and utilization levels. Our data depict less probable use of small 


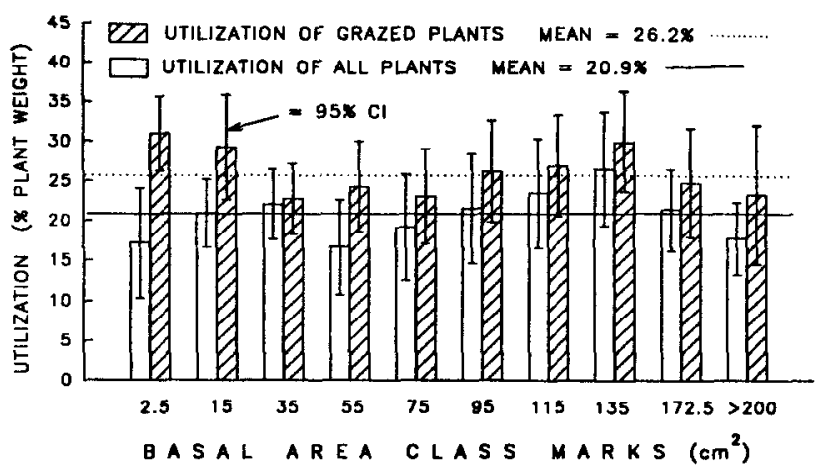

Fig. 3. Mean percent utilization by weight of crested wheatgrass plants occuring 10 basal area size classes. Paired means include estimates based on all plants within a size class and grazed plants only.

plants ( $<25-\mathrm{cm}^{2}$ basal area) and more frequent than expected use of medium-size individuals $\left(65-105 \mathrm{~cm}^{2}\right)$ with as much as a $43 \%$ difference in probability of defoliation between the 2 categories. This suggests seedlings and small plants may escape grazing, while medium-size plants experience a much higher probability of defoliation.

The selective foraging documented in our study may be related to bite width or bite size and the efficiency with which animals harvest forage from caespitose growth forms. Plants with diameters between 9 and $11.5 \mathrm{~cm}$ experienced the greatest probability of defoliation. Mean widths and the $95 \%$ confidence intervals of the incisors of our 2, 3, and 4+ year old Hereford $\times$ Angus cattle were $7.3 \pm 0.3,7.7 \pm 0.2$ and $9.0 \pm 0.3 \mathrm{~cm}$, respectively. We know that cattle use their tongues to draw forage to their mouths but have no measures on the efficacy of this feeding technique in expanding their effective bite size. Given the negative relationships detected between plant basal area and yield of forage per unit of basal area (Fig. 2), optimum returns per bite would be realized by grazing individual plants that approached maximum bite-size as opposed to multiple bites from larger tufts. Our data suggest harvest of 2 plants with equivalent basal areas would yield 2 units of forage, and defoliation of a single tuft with twice the basal area of the previous individuals would yield only 1.6 units of forage. Others have observed that sheep (Kenney and Black 1984, Arnold 1987) and cattle (Hacker et al. 1988) tend to graze areas where forage may be harvested most rapidly. We suggest this behavior may also extend to selection of individual tufts when cattle are grazing caespitose grasses. This hypothesis needs further verification under controlled conditions using either different classes of cattle or species of different mouth size and similar foraging technique.

Our cattle did not discriminate against plants greater than $105-$ $\mathrm{cm}^{2}$ basal area. Among 3 size classes of plants with mean basal areas spanning 20 to $314 \mathrm{~cm}^{2}$, Norton et al. (1983) found no discrimination by cattle after straw had been removed. This confirms Norton and Johnson's (1983) speculation that presence of old culms or straw in large tufts is most likely the only impediment to use of these plants by cattle.

In our analyses of grazed plant utilization, we detected a significant $(P<0.05)$ departure from the overall mean in the smallest size class where utilization was greater than average (Fig. 3). This could be attributed to the ease with which all stems of a small plant are removed with a single bite or to an effort by livestock to increase intake when an individual bite provides less biomass than normal. Norton and Johnson (1981) also detected shorter stubble in smaller tufts and noted that the uniformity of the grazing event for small plants more closely approximated a clipping treatment than the defoliation patterns exhibited on larger plants. Hacker et al. (1988) found no inverse relationship between plant basal area and utiliza- tion levels in their grazing studies. They speculated that their higher stocking rates, resulting in $90 \%$ of all plants being grazed, eliminated the selective grazing opportunities than Norton et al. (1982) had observed earlier.

A preponderance of plants in the small and largest basal area classes and fewer individuals in the mid-size classes most clearly describes the population of plants we sampled (Fig. 1). Whether this distribution is a product of previous selective use of mid-size plants by cattle or is typical of crested wheatgrass pastures is not known. We have no earlier data from the pastures describing plant basal areas or nearby exclosures where we can examine ungrazed crested wheatgrass. Hickey (1961) detected decreases in basal area of crested wheatgrass with herbivory, but the processes governing the break up of larger plants into more numerous but smaller individuals are not well understood (Butler and Briske 1988, Briske and Anderson 1990). Historically the pastures used in this study were grazed at a mean rate of 1.2 ha per AUM with no set season of use or rotation pattern employed over the past 18 years. Pastures used by Norton and Johnson $(1981,1986)$ and Hacker et al. (1988) had the greatest proportion (75\%) of plants in size classes less than $50-\mathrm{cm}^{2}$ basal area. Only $44 \%$ of our population had basal areas less than $50 \mathrm{~cm}^{2}$.

A reviewer questioned how associated forage species might have affected our results had we sampled in a more diverse setting. In response, interspecific variation in relative palatabilities are well documented, and the addition of other palatable forages to the stand would certainly alter the probabilities that plants of 1 species or another would be grazed. We suspect that within species having caespitose growth forms, however, that size preferences would still be exhibited by cattle as long as selective opportunity existed. High levels of utilization, however, would eliminate the opportunity to forage selectivity, and residual evidence of such behavior would be more difficult to detect. To our knowledge, however, this hypothesis has not been tested in mixed composition pastures.

\section{Conclusions}

In conclusion, the probability of crested wheatgrass tufts being grazed by cattle was significantly $(P<0.01)$ affected by size of basal area. With roughly $74 \%$ of all plants defoliated, we observed a $43 \%$ disparity in probability of defoliation between the smaller plants and the most likely to be defoliated mid-size tufts. This selective grazing may be eliminated if high levels of utilization are attained over a short duration. In extended grazing studies, however, even with high levels of utilization, favored plants may be grazed initially, and possibly repeatedly, and less desirable individuals grazed later. This may be especially important when grazing treatments span long periods of time, and plant responses to the earliest defoliations differ from later effects. Also, smaller plants, although they are less likely to be grazed than mid-size counterparts, may be more heavily and uniformly defoliated than larger tufts.

Implications of these findings focus primarily on scientific efforts. Because probabilities and intensities of defoliation by cattle were not uniform across size classes of plants, we urge that researchers be cognizant of these aspects of grazing behavior when individual tufts or tillers serve as experimental units in grazing studies. Selection of experimental units by researchers should be driven by the specific hypothesis being tested. When the focus is only on the responses of defoliated plants or tillers, a researcher could expect to have most the experimental units grazed by cattle, without resorting to a $100 \%$ rate of use, if sampling is stratified in the 65 to $105-\mathrm{cm}^{2}$ basal area range. Where hypotheses describe pasture or stand responses, however, a procedure assuring random selection of individual plants is required for unbiased interpretations. Finally, if one suspects potential confounding of data due to variation in the frequency of use or level of utilization on specific 
plants, measures of basal area can be acquired and tested as a covariate.

\section{Literature Cited}

Arnold, G.W. 1987. Influence of the biomass, botanical composition and sward height of annual pastures on foraging behaviour by sheep. J. Appl. Ecol. 24:759-772.

Balph, D.F., and J.C. Malechek. 1985. Cattle trampling of crested wheatgrass under short-duration grazing. J. Range Manage. 38:226-227.

Balph, D.F., M.H. Balph, and J.C. Malechek. 1989. Cues cattle use to avoid stepping on crested wheatgrass tussocks. J. Range Manage. 42:376-377.

Briske, D.D., and V.J. Anderson. 1990. Tiller dispersion in populations of the bunchgrass Schizachyrium scoparium: implications for herbivory tolerance. Oikos 59:50-56.

Butler, J.L., and D.D. Briske. 1988. Population structure and tiller demography of the bunchgrass Schizachyrium scoparium in response to herbivory. Oikos 51:306-312.

Ganskopp, D., R. Angell, and J. Rose. Response of cattle to cured reproductive stems in a caespitose grass. J. Range Manage. 45:401-404.

Hacker, R.B., B.E. Norton, M.K. Owens, and D.O. Frye. 1988. Grazing of crested wheatgrass, with particular reference to effects of pasture size. J. Range Manage. 41:73-78.

Heady, H.F. 1950. Studies of bluebunch wheatgrass in Montana and height-weight relationships of certain range grasses. Ecol. Monogr. 20:55-81.

Hickey, W.C., Jr. 1961. Growth form of crested wheatgrass as affected by site and grazing. Ecol. 42:173-176.
Kenny, P.A., and J.L. Black. 1984. Factors affecting diet selection by sheep. I. Potential intake rate and acceptability of food. Australian J. Agr. Res. 35:551-563.

Lentz, R.D., and G.H. Simonson. 1986. A detailed soils inventory and associated vegetation of Squaw Butte Range Experiment Station. Agr. Exp. Sta. Oregon State Univ., Corvallis Special Rep. 760.

Marten, G.C. 1969. Measurement and significance of forage palatability. p. D-1 D-55. In: R.F. Barnes, D.C. Clanton, C.H. Gordon, T.J. Klopfenstine, and D.R. Waldo (ed), Proc. Nat. Conf. on Forage Quality Evaluation and Utilization. Nebraska Center for Continuing Education, Lincoln, Neb.

Miller, R. 1966. Simultaneous statistical inference. McGraw-Hill Book Company, N.Y.

Norton, B.E., and P.S. Johnson. 1981. Pattern of defoliation by cattle grazing crested wheatgrass pastures. Proc. XIV Int. Grassl. Cong., Lexington, $\mathrm{Ky}$.

Norton, B.E., and P.S. Johnson. 1986. Impact of grazing on crested wheatgrass in relation to plant size. p. 275-279. In: K. Johnson (ed.) Crested wheatgrass: its values, problems, and myths; Symp. Proc. Utah State Univ., Logan.

North, B.E., P.S. Johnson, and M.K. Owens. 1983. Increasing grazing efficiency. Utah Sci. 43:110-113.

Norton, B.E., P.S. Johnson, C. Smith, and M.K. Owens. 1982. Spatial distribution of utilization by cattle grazing crested wheatgrass pastures. p. 199-200. Proc. Nat. Conf. Grazing Manage. Technology. Texas A\&M Univ.

Snedecor, G.W., and W.C. Cochran. 1967. Statistical methods. Iowa State University Press. Ames, Iowa. 